Bond University

Research Repository

\title{
Do intensive preoperative and postoperative behavioural interventions impact on health- related bariatric surgery outcomes? A systematic review
}

Marshall, Skye; Mackay, Hannah; Rich, Graeme; Isenring, Elisabeth

Published in:

Clinical Nutrition

DOI:

10.1016/S0261-5614(19)32413-6

Licence:

CC BY-NC-ND

Link to output in Bond University research repository.

Recommended citation(APA):

Marshall, S., Mackay, H., Rich, G., \& Isenring, E. (2019). Do intensive preoperative and postoperative

behavioural interventions impact on health-related bariatric surgery outcomes? A systematic review. Clinical Nutrition, 38(S1), s274. [MON-PO580]. https://doi.org/10.1016/S0261-5614(19)32413-6

\section{General rights}

Copyright and moral rights for the publications made accessible in the public portal are retained by the authors and/or other copyright owners and it is a condition of accessing publications that users recognise and abide by the legal requirements associated with these rights.

For more information, or if you believe that this document breaches copyright, please contact the Bond University research repository coordinator 


\section{Do intensive preoperative and postoperative behavioural interventions impact health-related bariatric surgery outcomes?}

BOND UNIVERSITY

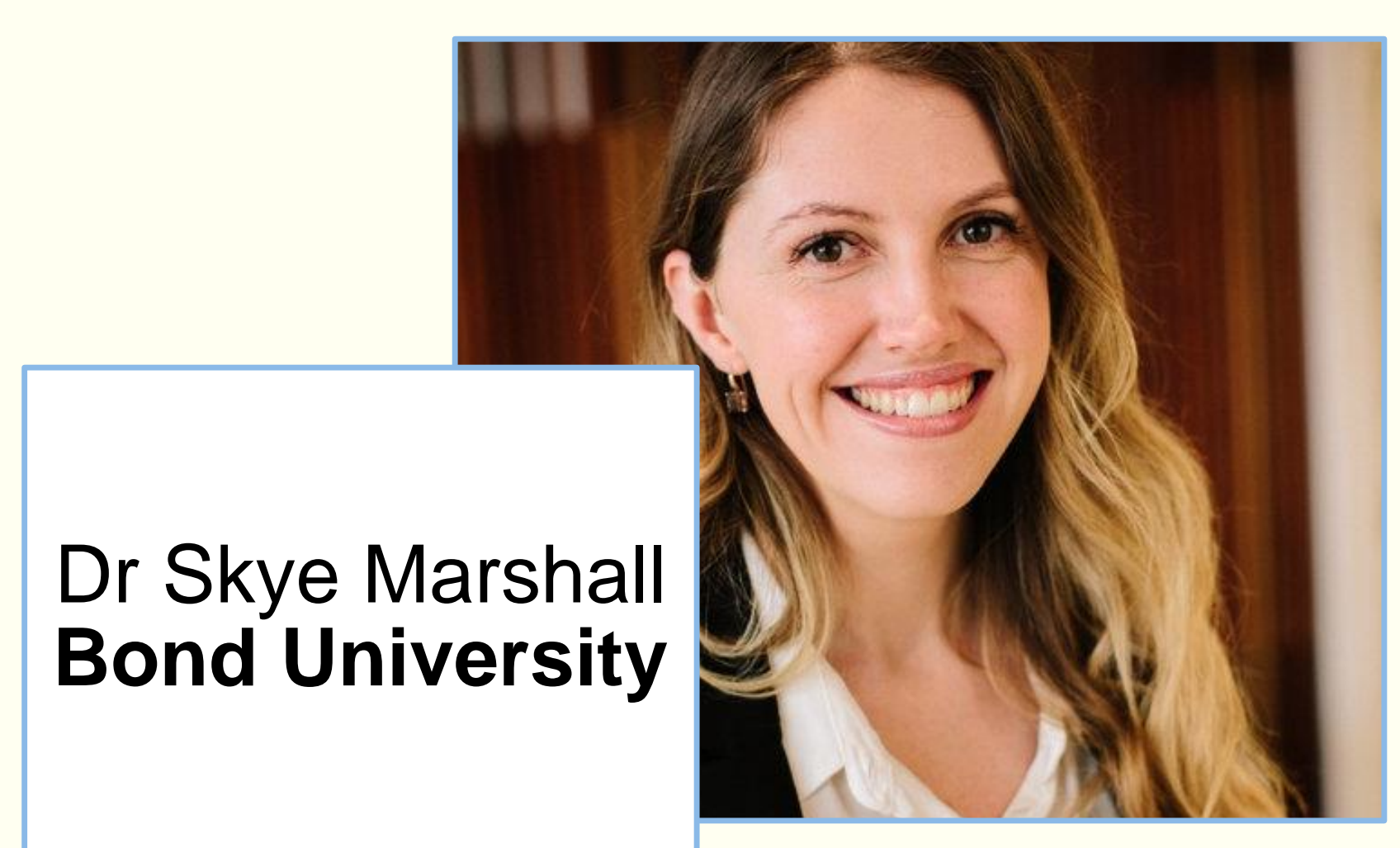

\section{A systematic review and meta-analysis}

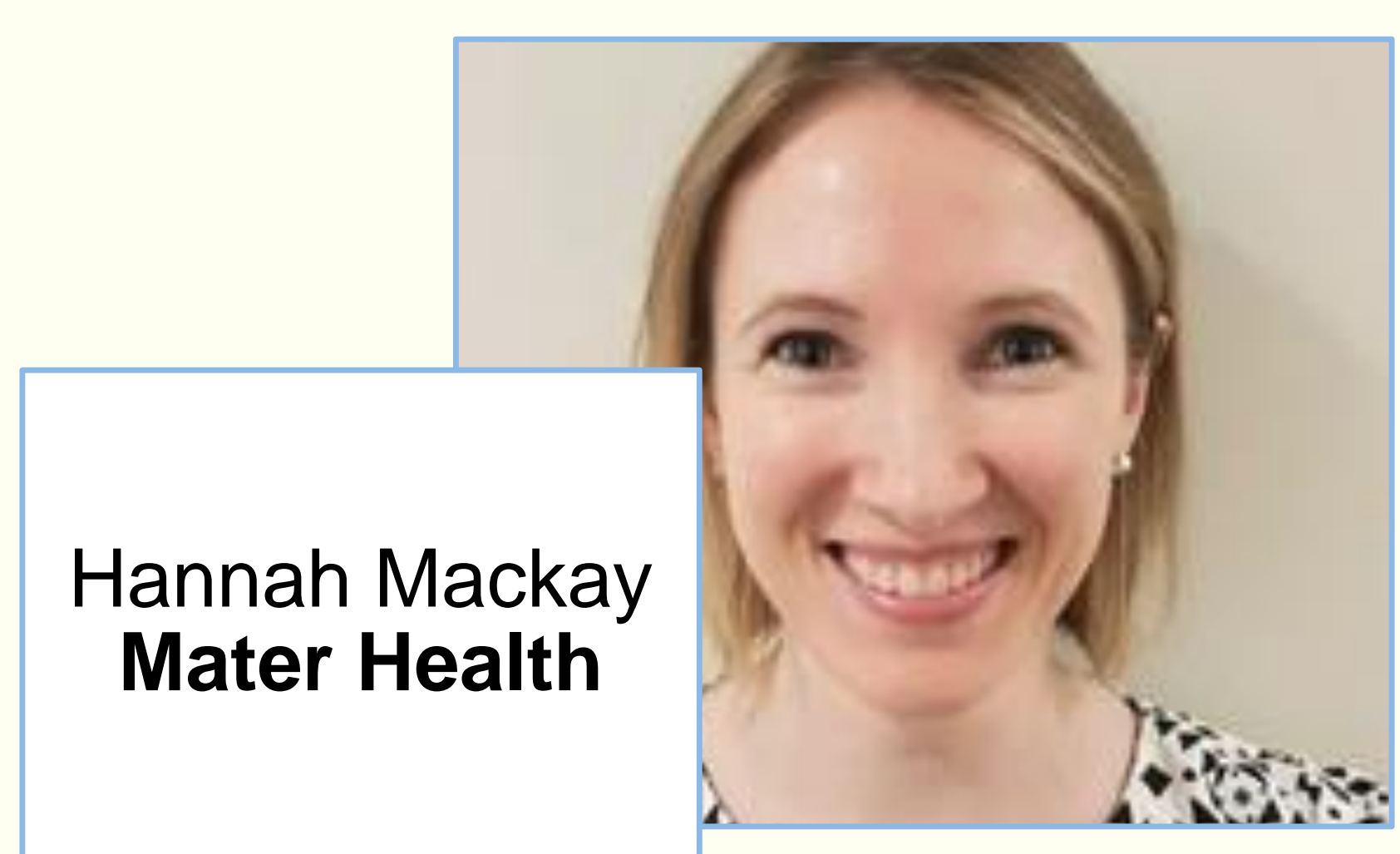

Although pre- and postoperative support by a multidisciplinary team (MDT) is recommended as best practice, it is unknown if intensive behavioural interventions improve outcomes beyond standard MDT support.

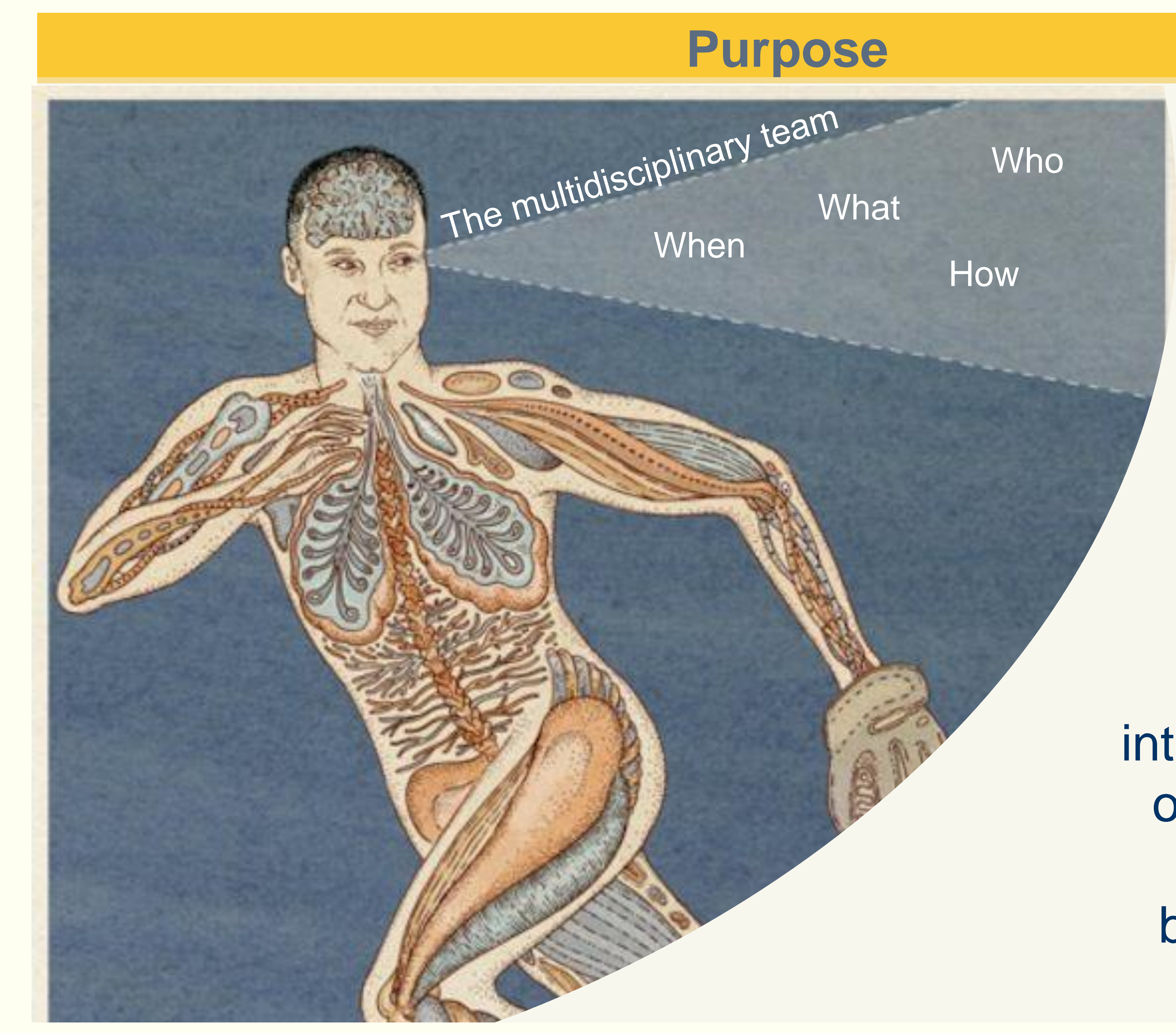

To evaluate the effect that intensive preand/or postoperative behavioural interventions have on health-related outcomes postbariatric surgery.
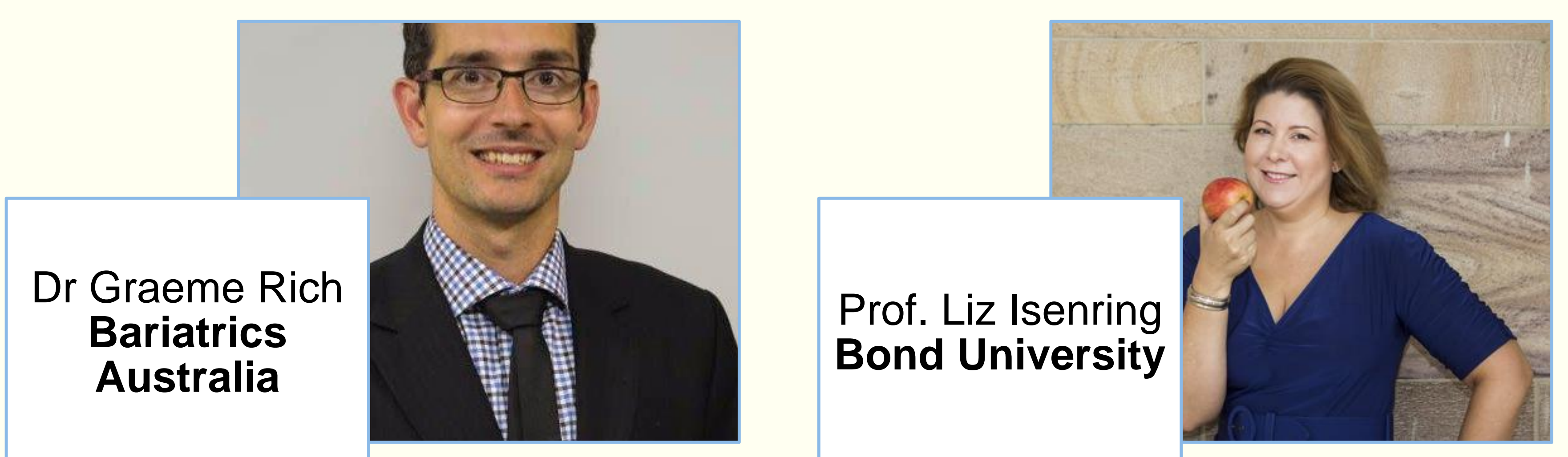

skye_marshall@bond.edu.au; @DrSkyeMarshall

\section{Methods}

Six databases were searched and 6,871 records screened for eligibility. Risk was assessed by Cochrane Risk of Bias tool, meta-analysis performed using RevMan, and confidence in the body of evidence for pooled outcomes appraised using GRADE.

\section{Findings}

There were a total of $n=953$ participants (mean age 33-46 years; $63-85 \%$ female). Risk of bias was unclear to high in all studies.

\section{MDT characteristics}

\begin{tabular}{l|l|l}
$\begin{array}{l}\text { Interventional MDT } \\
\text { characteristic }\end{array}$ & $\begin{array}{l}\text { Lifestyle \& nutrition } \\
\text { interventions } \\
n=4 \text { studies }\end{array}$ & \multicolumn{1}{c}{$\begin{array}{l}\text { Psychology interventions } \\
\text { n studies }\end{array}$} \\
\hline $\begin{array}{l}\text { - Added a health discipline } \\
\text { - Increased intensity }\end{array}$ & $\cdot 100 \%$ & $\cdot 100 \%$ \\
\hline Interventionists & $-100 \%$ & $\cdot 80 \%$ \\
& $\cdot 75 \%$ dietitian & $\cdot 20 \%$ physiotherapist \\
& $\cdot 25 \%$ surgeon & $\cdot 80 \%$ psychologist \\
& Mostly counselling & $\cdot 20 \%$ psychiatrist \\
Content & & $\begin{array}{l}\text { Mostly cognitive behavioural } \\
\text { therapy }\end{array}$
\end{tabular}

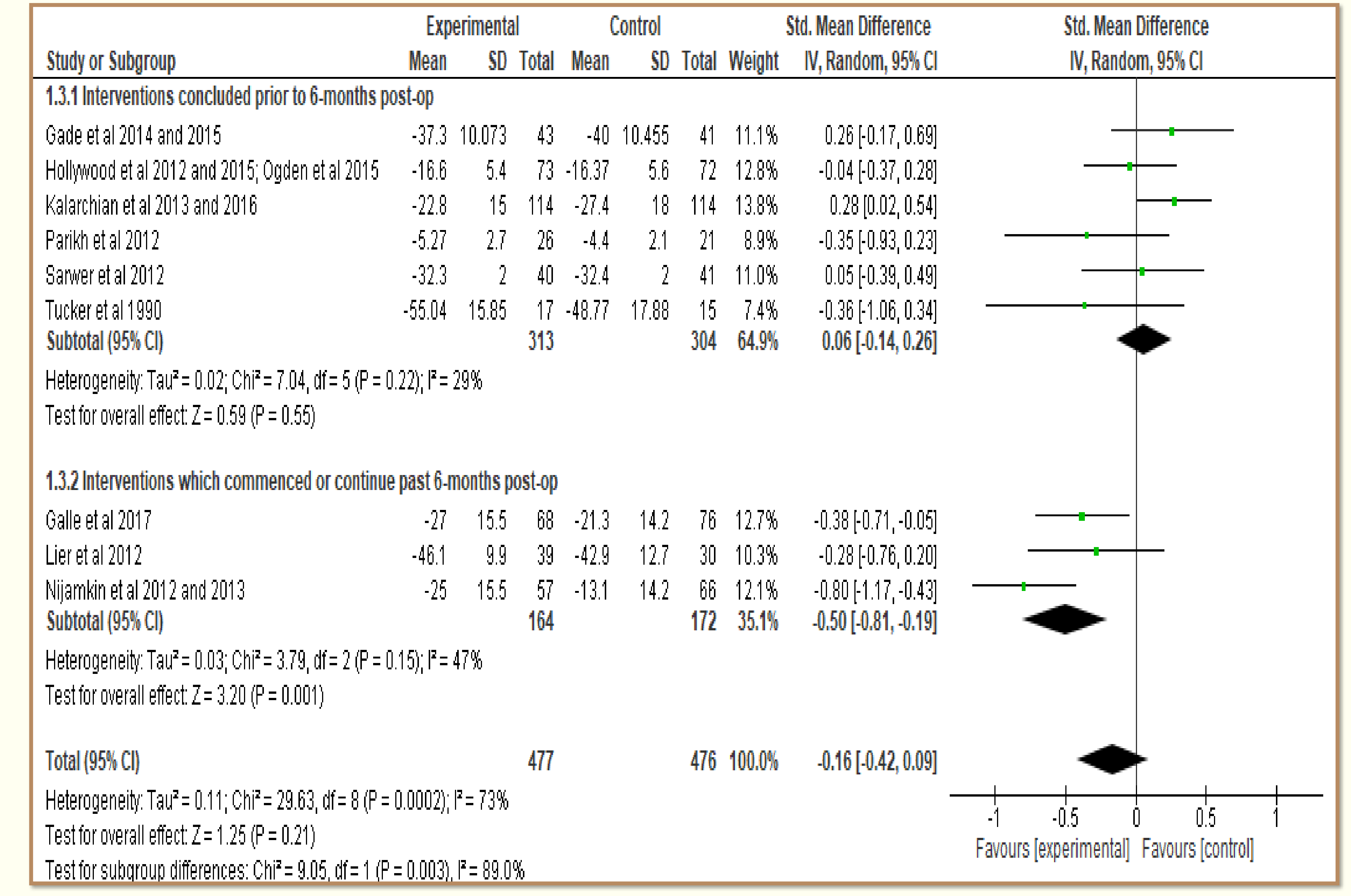

Intensive nutrition, lifestyle, and psychology focused interventions which continued past or commenced at 6-months post-op had greater weight loss $(7.8 \%[95 \% \mathrm{Cl}: \mathbf{2 . 9}, \mathbf{1 2 . 6})$ compared to those that in usual care. Interventions which concluded prior to 6-months post-op had no effect on weight loss compared to usual care (GRADE: very low confidence in estimated effect).

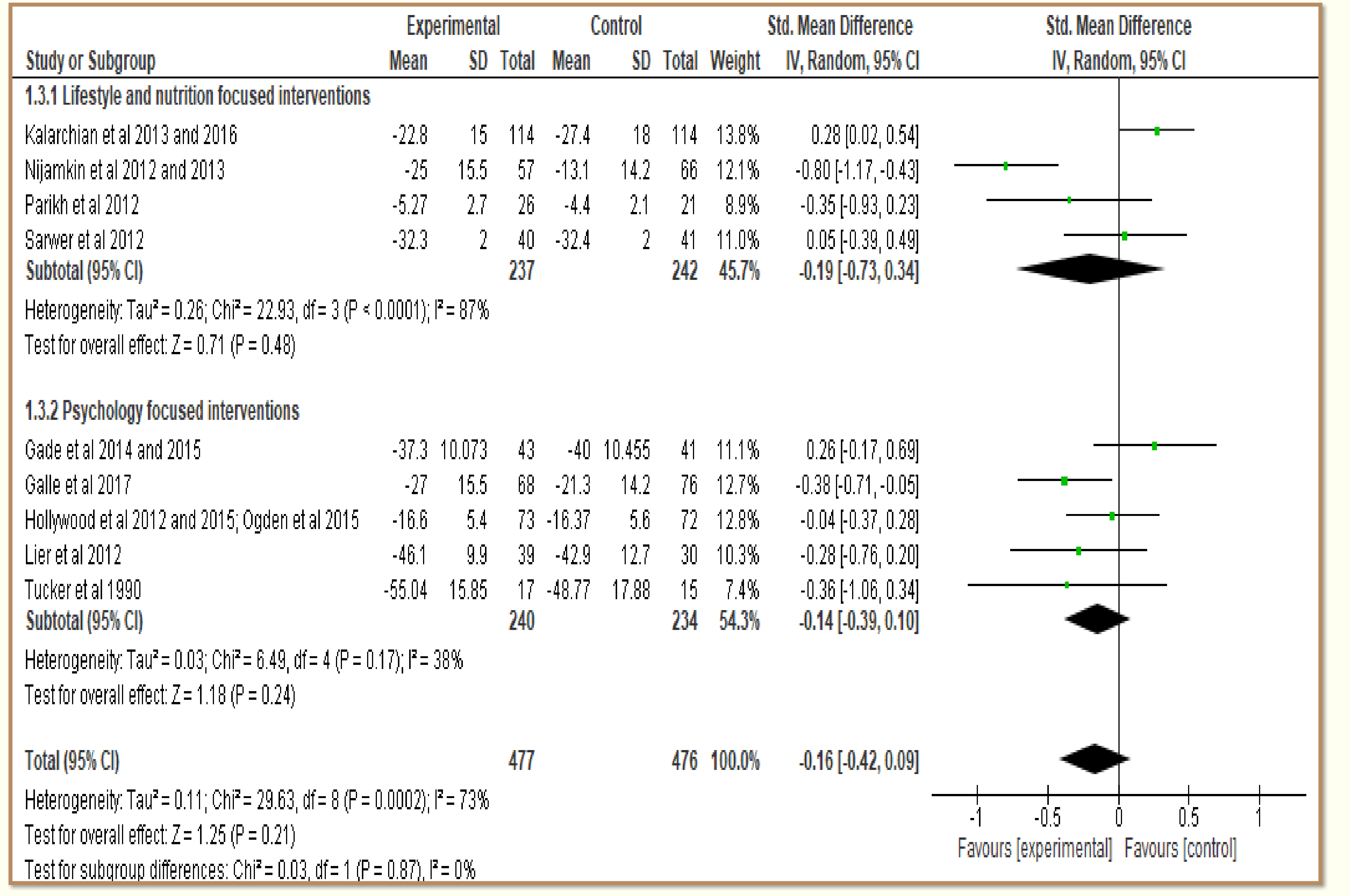

Intensive behavioural pre- and/or postoperative interventions delivered by an MDT had no effect on weight loss, with no difference between subgroups (lifestyle \& nutrition interventions versus psychology interventions)

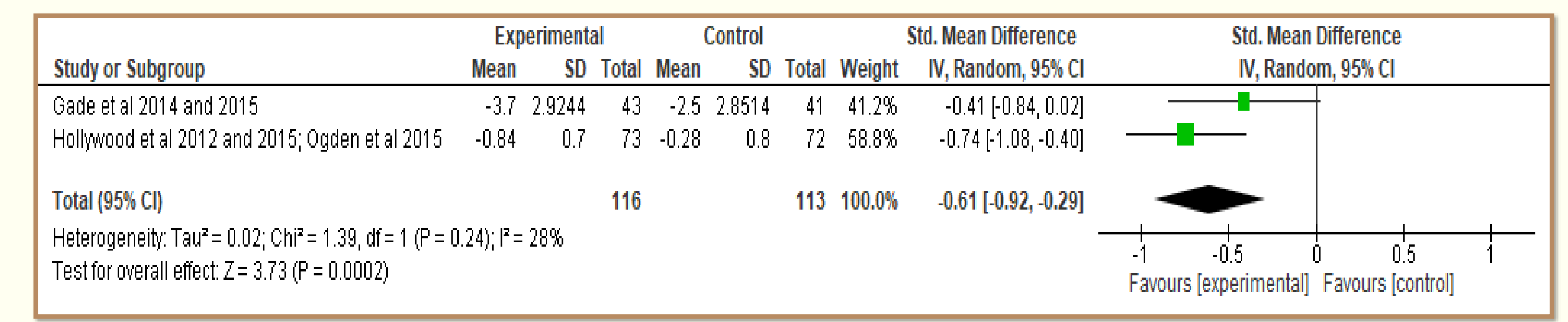

Intensive psychology focused interventions decreased depressive symptoms compared to usual care (GRADE: very low confidence in estimated effect).

\begin{tabular}{l|l}
\hline Other health-related outcomes & Pooled outcome \\
\hline Anxiety & No effect $(p=0.16)$ \\
Systolic blood pressure & No effect $(p=0.91)$ \\
$\begin{array}{l}\text { Diastolic blood pressure } \\
\text { Insufficient data to pool quality of life, blood lipids, adverse events, } \\
\text { comorbidity incidence, glycaemia. }\end{array}$
\end{tabular}

Implications for practice

Pre- and postoperative MDT support of bariatric surgery is essential to ensure patient safety; however, intensive behavioural interventions of any type appear to be effective only if they continue past or commence at 6-months post-op.

Confidence in the estimated effects are very low due to lack of blinding in studies and a poor of precision of the pooled estimates; further research will strengthen confidence in the body of evidence. 